Research Article

\title{
Study on Parameter Optimization and Mechanism of Rigid-Flexible Coupling Underground Engineering Structure of Steel Panel and Polymer
}

\author{
Dengping Hu, ${ }^{1}$ Chunyan Wang, ${ }^{2}$ Zhe Luo $\mathbb{D}^{3},{ }^{3}$ and Xuanxuan Chu $\mathbb{D}^{4}$ \\ ${ }^{1}$ School of Civil Engineering, Guangzhou University, Guangzhou 510006, China \\ ${ }^{2}$ China MCC20 Group Co., Ltd., Shanghai 201900, China \\ ${ }^{3}$ College of Intelligent Manufacturing, Hunan University of Science and Engineering, Yongzhou, Hunan 425199, China \\ ${ }^{4}$ Nottingham Transportation Engineering Centre, Faculty of Engineering, University of Nottingham, University Park, \\ Nottingham, NG7 2RD, UK \\ Correspondence should be addressed to Zhe Luo; lzxky@huse.edu.cn
}

Received 2 November 2019; Revised 20 November 2021; Accepted 27 November 2021; Published 11 December 2021

Academic Editor: Hui Yao

Copyright (C) 2021 Dengping Hu et al. This is an open access article distributed under the Creative Commons Attribution License, which permits unrestricted use, distribution, and reproduction in any medium, provided the original work is properly cited.

\begin{abstract}
Polymer grouting is carried out between the steel panel and surrounding soil in underground engineering, and the polymer material consists of isocyanates and polyols. The isocyanate/polyol composite slurry expands rapidly due to chemical reaction and solidifies immediately. Then, a dense impermeable polymer layer is formed after rapid expansion of isocyanate and polyol, which is widely used for ground reinforcement and foundation remediation. Thus, a steel panel-polymer composite structure is developed. Mechanical properties of the steel panel-polymer structure are studied. The results show that the steel panel-polymer structure exhibited excellent mechanical properties. The steel panel and polymer layer should be designed above $3 \mathrm{~mm}$ and $10 \mathrm{~mm}$ in thickness, respectively. The steel panel showed superior mechanical properties to those of polymer layers. Considering good rigidity of the steel panel and good flexibility of the polymer layer, the steel panel and polymer layer presented perfect interfacial contact. It is concluded that the mechanical properties of the whole structure were increasingly enhanced with the increase of the steel panel thickness and the structural flexibility increased with the thickness of the polymer layer. Besides, the combination of the steel panel and polymer layer could also improve the mechanical properties of this coupling structure. This study provided an initial attempt for investigating the feasibility of applying polyurethane foam to steel panels in underground engineering. The stress analysis along the grouting direction inside the prefabricated wall was conducted. It may lay the foundation for further application of polymer grouting in underground engineering.
\end{abstract}

\section{Introduction}

Polymer materials exhibit the properties of low density, low price, and easy formation to porous media and perform excellently in reducing seismic response, oscillation, and stress amplitude. From previous experimental research [1], it has been revealed that the materials possess perfect properties in flame retardancy, pressure resistance, and energy absorption, etc. A composite polymer material has been studied, and its special nature and functions were also revealed.

For underground space development, the coupling structure includes the steel pile support, the steel panels, and grouting polymer between surrounding soil and steel panel. The polymer layer is mainly used to reinforce soil, and the coordination between the deformation of steel panels and polymer layer will also promote the reinforcement of surrounding soils. Thus, the overall scale and the thickness of the steel panel and polymer layer play an important role in the overall lateral displacement of steel panel and the overall deformation of pile foundation. The application of polymers to foundation engineering provides reference for applying the polymer-steel panel structure to underground engineering. The overall structural characteristics of the polymer-steel panel are studied by referring to the laminated 
structure model of steel panel, i.e., grouting a layer of polymer below the steel panel. All of these provide a theoretical basis for the application of the steel panel-polymer coupling structure.

Currently, polyurethane composites have been widely promoted and utilized, and high-performance composite polymer materials have demonstrated excellent thermal stability, electrical conductivity, and high strength. In terms of the above properties, polymer composites present great development potential in many aspects [1-5]. The domestic and overseas research mainly focus on adding carbon fiber into composite materials [6-12]. Compared with other new materials, this will indirectly reduce the density and affect the molecular particle size. Recently, there are some other studies in the carbonaceous material added to the polyurethane [13-16]. For example, carbon black [17, 18] can be gradually added to aqueous polyurethane materials. Since the molecular chain can also cause different physical properties of different polyurethane materials, more functional materials now can be used to produce polyurethane foam [19-21] and adhesive coatings, etc. Then, the products are incorporated polyurethane products and plastic products for many different purposes and can also be widely used in construction [22, 23], transportation, and other industries.

According to the statistics in 2014, the global consumption of polyurethane has exceeded 21.5 million tons, and the foam products have become the focus of polymer material design with the annual consumption exceeding 11.5 million tons [24]. In addition, polyurethane materials used in the project also become a main branch of polyurethane materials with an annual consumption of about 2 million tons. As a research hotspot, polyurethane composites have the following significant characteristics [25]: (1) adjustable hardness, i.e., the formula of polyurethane material is continuously adjusted so that the hardness range of polyurethane can be distributed between Shao A10 and Shao D90; (2) good physical and mechanical properties, e.g., it has higher tear and tensile strength than general rubber; (3) good abrasion resistance, oil resistance, radiation resistance, ozone resistance, and adhesion and excellent biocompatibility.

Aiming at the relative properties of polymer materials, many scholars have done more research [26-31]. The related properties of polymers are well explained. The combination of polymer material and steel structure is well verified, and it shows that the polymer can be better bonded to the steel plate. A steel panel-polymer composite structure layer can be developed, with highly positive attenuation performance on deformation.

For the rapid development of polymers, especially polyurethane composites, an increasing number of studies have been performed on the Sandwich structure of core foams, mainly including polyurethane foam, polystyrene foam, polypropylene, polycarbonate, and PVC foam [32-38], whilst with respect to the three-layer composite structure, more core structures are designed for composite materials [39]. The core structure has characteristics of large rigidity, light weight, high strength, good corrosion resistance, good isolation performance, and good fatigue endurance [40]. The structure of polyurethane composite laminated core board has more advantages [41-44]. For example, the relative heterogeneity is small. Since the polyurethane material structure is sandwiched between the surrounding structures, the polyurethane composite core layer structure is homogeneous and dense, and the cavity filling is perfect. The composite Sandwich structure and the polymer composite structure can also be firmly condensed on the surface material due to the excellent support of the cavity Sandwich material structure. This new material structure of composite panels has been explored in the domestic and international studies and has been widely used in practical engineering. It is further promoted and applied with the release of some guidance documents.

In addition, polyurethane composites are lightweight and have other functions, e.g., the material experiences some consolidation after the reaction, with relatively light weight and low relative density. Although the polymer strength is lower than that of asphalt concrete, it has better expansion and contraction performance than asphaltic mixtures [45-47]. The polymer anisotropy tested in the relevant triaxial experiment is equivalent to that of the concrete, which also has better performance $[48,49]$. The composite polymer functional material can achieve rapid curing and obtain $90 \%$ of the molding composite strength in 15 minutes. The composite exhibits inertia, no deterioration and shrinkage, good durability, and high impermeability. The cured material has good waterproof and antipermeability, and no pollution to the environment and water. Many scholars have studied the relevant properties of the cross section of the composite structure, and the performance of the related materials has been greatly improved. The composite bonded structure of the polymer and the steel panel also has better performance, which greatly improves the performance of the steel panel as well as overall mechanical properties [50-53].

A continuous antiseepage curtain wall is constructed behind the steel sheet using polymer grouting, which is waterproof and can strengthen the surrounding soil. In general, it can be concluded that the polymer material is an excellent grouting material with excellent comprehensive properties and have been widely used in geotechnical engineering. It should be mentioned that, compared with current impervious materials, polyurethane foams have outstanding characteristics in clay slurries, grouts, reinforced concrete, and plastic concrete, i.e., they exhibit good crack resistance, are light in weight without additional stress to the structure, and has rapid solidification process. Thus, the construction period will greatly decrease. As a kind of antiseepage material, polymer materials have self-evident advantages in seepage prevention of dams and embankments. However, studies have been rarely conducted on the application of polymer materials to the steel panel in impervious engineering systems.

\section{Polymer Material Tests}

The polymer grouting material reacted with a certain proportion at $80^{\circ} \mathrm{C}$ for 2 hours in terms of isocyanate and 
polyether polyols (dehydrated at $110^{\circ} \mathrm{C}$ ). Then, $10 \%-30 \%$ diluent, $0.2 \%-1 \%$ surfactant, $0.1 \%-0.5 \%$ catalyst, and $5 \%-$ $10 \%$ flame retardant were added. The red material indicates the methyl phenyl isocyanate, and the blue material indicates a mixture, containing $45 \%$ of polyols (sucrose multivariate benzene anhydride polyester and polyether polyol), 36\% of phosphorus-containing flame retardants, $15 \%$ of the physical foaming agent, $2 \%$ of the amine catalyst, $1 \%$ of silicon surface active agent, and $1 \%$ of the chemical foaming agent (water). The designed ratio was calculated according to the percentage. The following is the chemical reaction equation of some materials, as shown in Figure 1, and the process was expressed as equations (1) and (2).

The polymers consist of isocyanates and polyols. The uniaxial compression of stress-strain curves and morphology of polyurethane polymer samples at different densities after loading were demonstrated. During the application of uniaxial pressure, the response of the sample experienced three stages, as shown in Figure 2(a), elastic, yielding, and densification stages. When the strain was less than $5 \%$, it was in the elastic stage. Under small compressive stress, the bubble holes interacted with each other, and the irregular holes were first compressed into a regular sphere, which produced uniform deformation after compression. The edge of the bubble hole was caused by external force buckling. The bubble busted, and the material reached the yield strength with the strain lying between 5\% and 50\%. At the yielding stage, the bubble collapse of the structure continued to occur, and the strain continuously increased, whilst the stress remained constant or slightly increased. When the strain reached $50 \%$ or above with the bubble holes inside the structure being substantially destroyed, the material entered the densification stage. The material was compressed and pressed, and the stress significantly increased as the strain increased.

The main components of the polymer material are isocyanates and polyols. According to the study on the polymer [43], surface tension and surface energy existed at the interface of the vesicle. The surface energy increased with the surface area, whilst the system stability decreased. The shape of the pores in the sample was spherical, under which the pores had the smallest specific surface area. The pores were far apart and did not interact with each other to ensure the minimum total surface energy of the system. The existing space was inadequate to fill pores into a sphere, and then the pores would reduce their sphericity and gradually became polyhedral with larger diameters. The edge of the pore was easily bent under an external force, and thus caused sample failure under the uniaxial compression. The stress-strain curve of the material under uniaxial compression is shown in Figure 2(b). When the strain was less than 5\%, the material was in the elastic stage and the stress increased linearly with the deformation. After the strain exceeded 5\%, the yield surface was reached and the strain continued to increase, but the stress remained constant or grew slowly. The transition from elasticity to yield occurred at a strain of about $5 \%$. Therefore, the corresponding stress value at a compressive strain of $5 \%$ was taken as the compressive strength. The average compressive strengths of the samples with two different densities were 5.6 and $12.9 \mathrm{MPa}$, respectively.
Reaction of isocyanate with alcohol:

$$
\mathrm{RNCO}+\mathrm{R}^{\prime} \mathrm{OH} \longrightarrow \mathrm{RNHCOOR}^{\prime}
$$

Reaction of isocyanate with water:

$$
2 \mathrm{RNCO}+\mathrm{H} 2 \mathrm{O} \longrightarrow \mathrm{RNHCONHR}+\mathrm{CO}^{\prime}
$$

\section{Mechanical Theory of Polymer Materials}

Based on the specific properties of the polyurethane polymer composite, the constitutive model of the composite can be determined. When the overall external force of the composite material is applied, it can be transferred to the next interface through the basic interface of the distributed load. Under a certain interface strength, the shear stress shows the largest value at the end of the material and the smallest value in the middle. The tensile stress acting on the composite is derived from the cumulation of shear stress from the end to the middle. Thus, the tensile stress exhibits the smallest value at the end and the largest value in the middle. The material parameters and mechanical properties of the polyurethane polymer were continuously investigated. Based on the stress and deformation of the polymer materials, a stress-strain model can be established. $\sigma$ represents the tensile stress in any direction, $\sigma_{\max }$ denotes the maximum stress, $\bar{\sigma}$ is the mean stress, $l$ represents the composite fiber with a certain length, $l_{0}$ indicates the fundamental unit length of the composite material, and $\beta$ represents the composite material coefficient. According to the mechanical properties of the composite materials in different directions, it can be set that the orthotropic materials have three orthogonal planes, and the composite materials are denoted as orthotropic materials. For orthogonal anisotropic materials, the average tensile stress acting on the composite fiber is expressed as [26]

$$
\bar{\sigma}=\frac{1}{l} \int_{0}^{l} \sigma \mathrm{d} l=\sigma_{\max }\left[1-(1-\beta)\left(\frac{l_{0}}{l}\right)\right], \quad l \geq l_{0} .
$$

When the matrix of the composite material is an ideal plastic material, the tensile stress on the composite fiber gradually increases from zero at the end of the material. When $\beta=1 / 2$, equation (3) [26] can be expressed as

$$
\bar{\sigma}=\sigma_{\max }\left[1-\frac{l_{0}}{2 l}\right] \text {. }
$$

\section{Physical Model Tests}

Isocyanate/polyol composite slurry was used for the chemical reaction, with rapid volume expansion and immediate curing characteristics. It can achieve the function of consolidating the foundation, seepage plugging, and filling voids. The polymer showed good hydrophilicity, which immediately undergo polymerization reaction upon contact with water, disperse, emulsify or foam, expand, and consolidate with sand, stone, and soil into an elastic consolidation body, quickly plug cracks, and permanently stop 


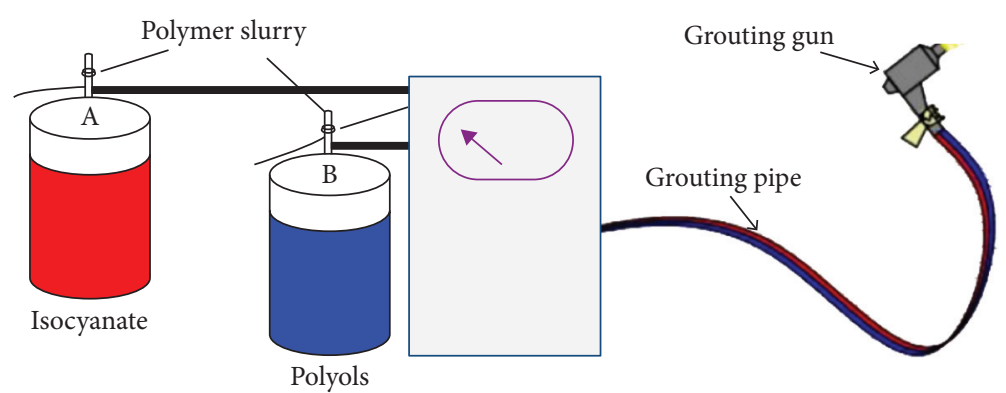

FIGURE 1: Reaction of two-component high polymer.

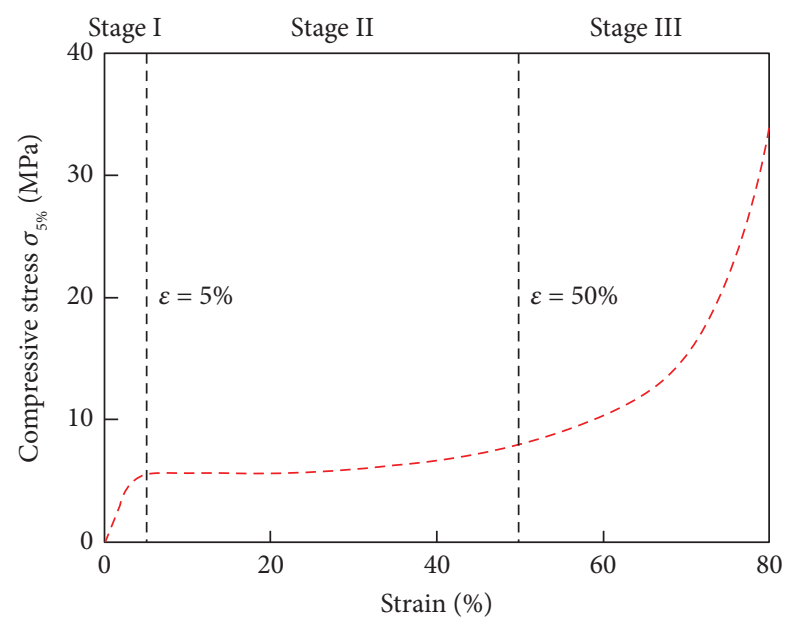

(a)

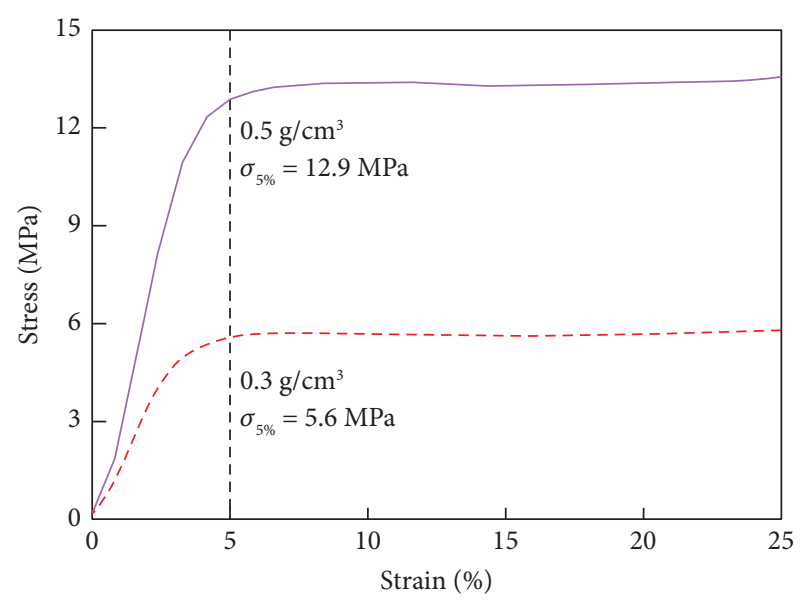

(b)

Figure 2: Polymer material test. (a) Stress strain analysis of polymer [42]. (b) stress strain analysis at different densities of polymer [43].

water migration. The detailed construction processes are presented in Figure 3. (a) Drilling support pile hole; (b) support pile installation; (c) connect the crown beam; (d) layered excavation soil; (e) layered installation of steel panel structure; (f) grouting behind the steel panel; (g) install the waist beam; (h) continue to excavate the soil layer and install steel panel retaining structure; (i) remove the waist beam; (j) recycle steel panel; (k) recycle the crown beam; (l) backfill the pile hole by compaction [44].

After grouting, a layer of impervious flexible polymer layer was formed between the steel panel and the soil. The polymer can be well bonded to the steel panel and exhibit good mechanical properties. The structure of the steel panelpolymer composite can play a good coupling role. In terms of mechanical properties in all respects, the steel panel is shown in Figures 4(a) and 4(b). The original length range was set as $1250 \mathrm{~mm}$ in the length direction, and the original rule in the height direction was set as $560 \mathrm{~mm}$. Since the depth of the pile foundation was different, the pile foundation settlement after the steel panel subsided was obtained according to the relationship of surface settlement. The stiffness can be measured by applying a vertical force on the side of the panel. When the polymer was grouted into the steel sheet, the polymer and the steel sheet condensed into a whole structure, and a buffer layer was formed between the polymer and the steel sheet. The bridge structure with good support structure and poor soil rigidity also has a good antiseepage effect. The creep deformation and lateral displacement of the soil will act as a buffer under the action of the polymer/steel composite structure, ensuring that the steel panel and the side soil were tightly bonded to the wall. After grouting between the steel panel and soil, a thin polymer layer structure with a certain strength was formed, which can play the role of water barrier and deformation resistance and has great engineering application potential. By grouting after the steel panel, the deformation of the overall structure decreased, although residual stress was generated, but the impact on the structure was small. Therefore, it is generally unnecessary to consider the buckling deformation of the steel panel.

\section{Effects of Polymer Layer Parameters on Steel Panel}

\subsection{Effects of Height-to-Length Ratio at Different Polymer Thicknesses}

(1) Since the polymer only showed impermeability with a thickness over $10 \mathrm{~mm}$, the polymer layer thicknesses were designed as 10,15,20,25, and $30 \mathrm{~mm}$, respectively, as illustrated in Figures 5(a) 5(e). With polymerization, the shear resistance of the composite 

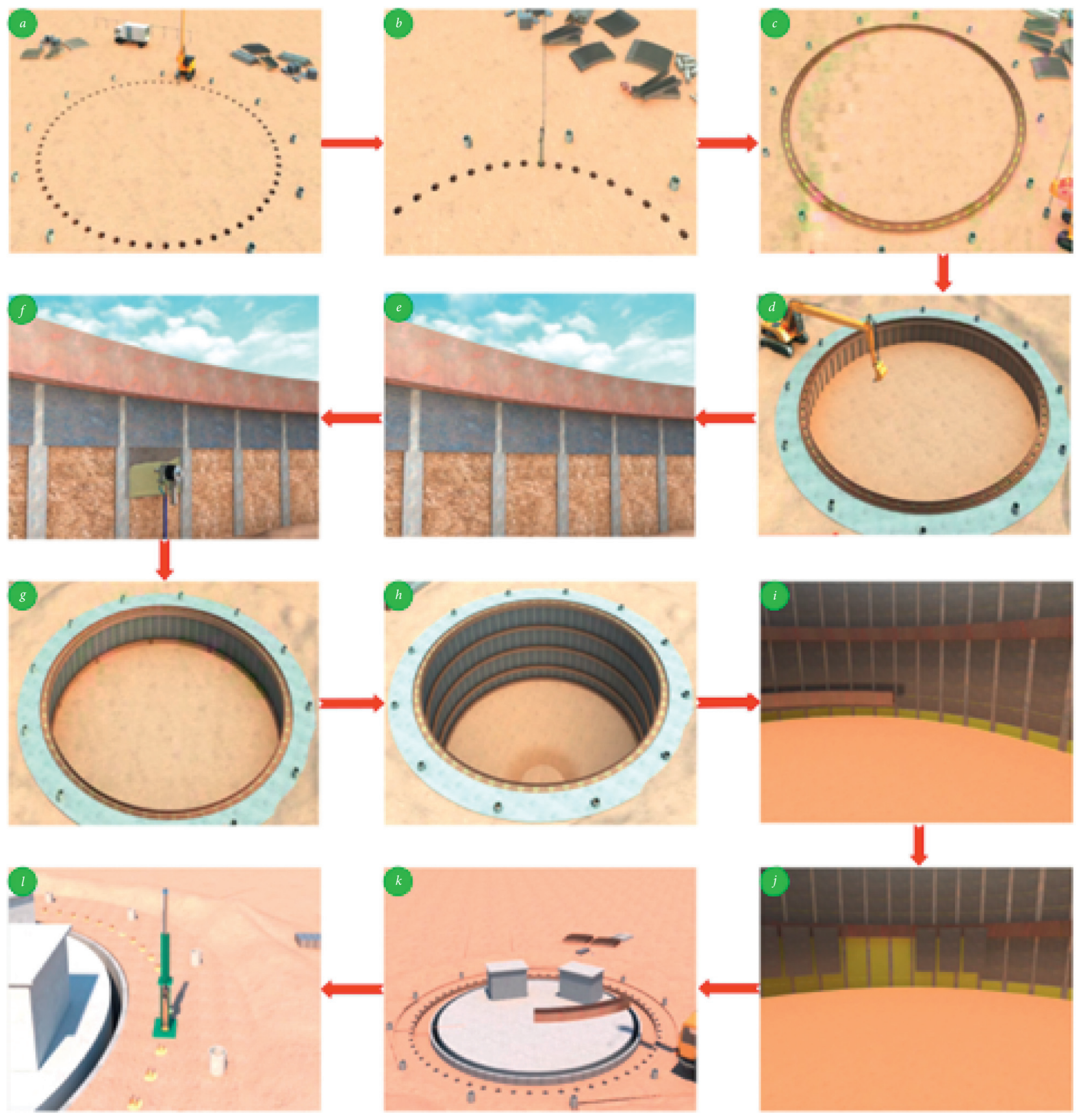

FIgURE 3: Construction technology process [44].

structure increased with the thickness of the impervious polymer layer. The polymer was reinforced, which played an important coupling role in the antiseepage layer of the steel panel. Thus, the longitudinal shear stress of the steel panel was effectively transferred.

(2) It can be seen from the slope of the inclined line that as the length of the steel plate-polymer increased, the vertical shearing capacity of the steel panel-polymer structure gradually increased. When the height-tolength ratio increased from 0.5 to 0.8 , the shear capacity increased by 1.8 times. When the height-to- length ratio increased from 0.8 to 1 , the shearing capacity rose by a factor of 0.8 , whilst it may increase by a factor of 6 with the high height-to-length ratio varying from 0.5 to 1.5 .

(3) When the height-to-length ratio of steel panelpolymer layer was 1.5 , the increase of shearing capacity of the composite structure was attributed to the increasing length of shearing section and the increase of reaction shear resistance of steel panel to polymer layer.

(4) From the slope of the slant line, the slope of the inclined line gradually decreased. Under the 


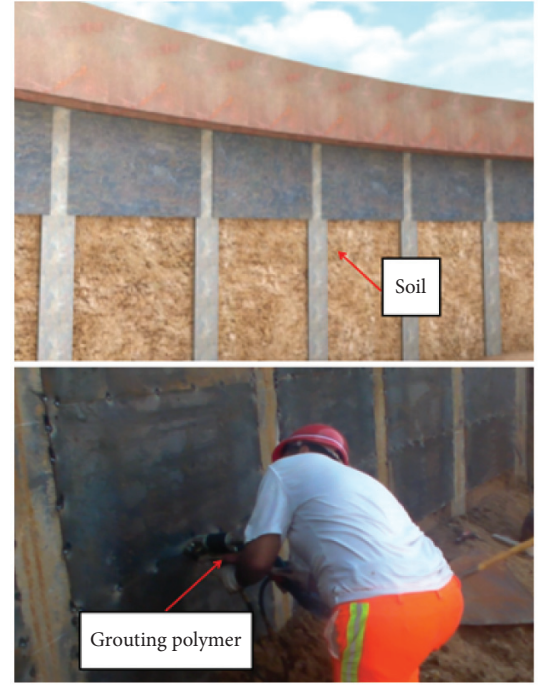

(a)

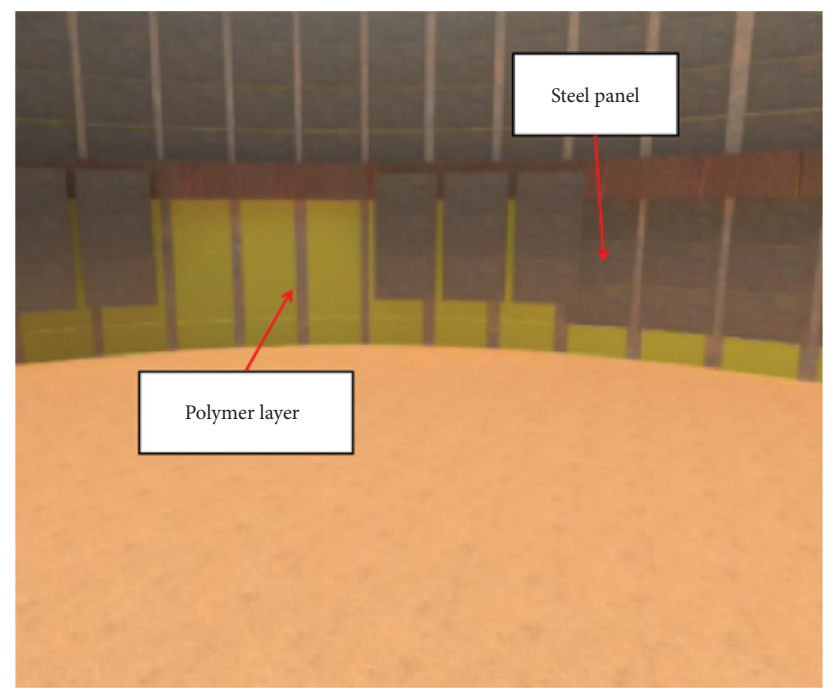

(b)

Figure 4: Formation of the polymer-steel panel coupling structure [44]. (a) Grouting is carried out behind the steel panel. (b) Polymer composite layer is behind the steel panel.

condition of increasing the thickness of polymer layer, the shearing capacity of steel panel-polymer composite structure gradually increased with the increase of the high-to-length ratio of polymer layer. As the longitudinal height of steel panel-polymer increased, the shearing capacity of steel panelpolymer structure gradually increased with the thickness of polymer.

\subsection{Effects of Polymer Thickness on the Composite Structure}

(1) In order to study the effect of the polymer layer thickness on the mechanical properties of the steel panel-polymer composite structure, polymer layers of different thickness were designed. The two-factor analysis was mainly conducted under the conditions of steel panel and polymer, with the polymer layer. As the polymer thickness increased, the shearing capacity of the composite structure increased. The thicknesses of the steel panel were designed as 3, 6, 9, and $12 \mathrm{~mm}$, respectively. The thicknesses of the polymer layer were selected as $10,15,20,25$, and $30 \mathrm{~mm}$, respectively. Thus, the shearing capacity curve of the composite structure was analyzed at different thicknesses of steel panels and polymer layers. The shearing capacity curves are demonstrated in Figures 6(a) 6(d).

(2) It can be seen that the slope of the inclined line was relatively stable. The coupling curves of the polymers in the elastic phase transition structure at different thicknesses were in good agreement, and the slopes of the initial curve were slightly different. It may reveal that the polymer layer will not affect the shear resistance of the composite structure and the shear force of the steel panel. Therefore, the shearing capacity was not sensitive to the thickness of the polymer.
(3) The increase of polymer thickness had few effects on the yield bearing capacity of steel panel. Since the steel panel and polymer composite structure reached the plastic deformation stage, the bearing capacity of shear wall remained relatively stable with the increase of the thickness of steel panel, i.e., no clear decline stage. The polymer layer has good ductility. With the increase of polymer thickness, the deformation resistance of the polymer-steel panel composite structure was gradually enhanced under different conditions.

(4) From Figures 6(a) 6(d), the sloping line did not change greatly. According to the plastic deformation and displacement curve of steel panel and polymer under the constant thickness of steel panel, the mechanical properties of the composite structure of steel panel and polymer increased with the increase of the thickness of the polymer, but the increase rate gradually decreased. The increase rate of shear resistance of the composite structure was far less than that of the polymer. Therefore, when considering increasing the thickness of polymer layer, it is necessary to consider not only the economy of the polymer layer but also whether the thickness of the polymer layer could cause better flexibility of polymer layer to the steel panel.

\section{Derivation of Theoretical Model}

Under the action of longitudinal shear force, the steel panel and the polymer can be closely bonded together. Under the stress condition (as shown in Figure 7) [29], the steel panel and the polymer structure have a certain shear force in the direction of cross section. In order to study the overall stiffness of the steel panel and the polymer, the slope at the origin under loading can be set as initial stiffness, which can 


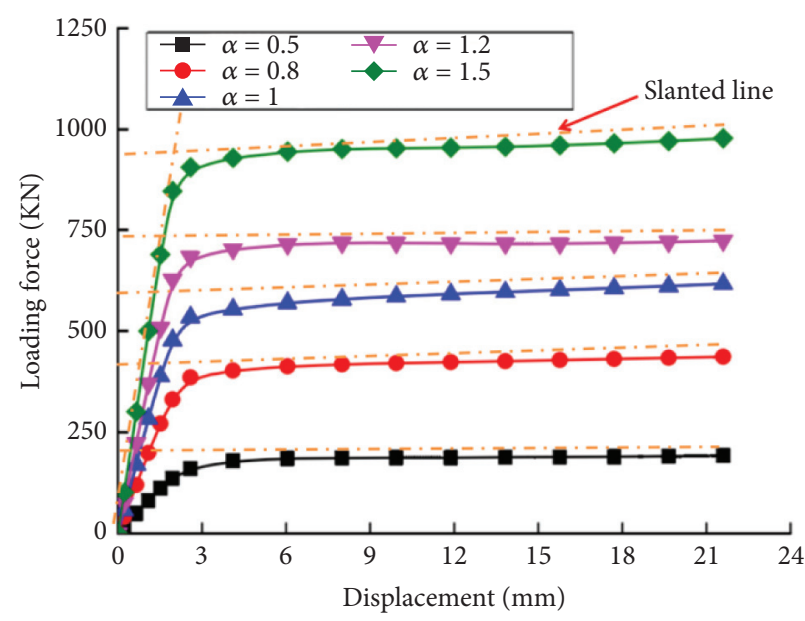

(a)

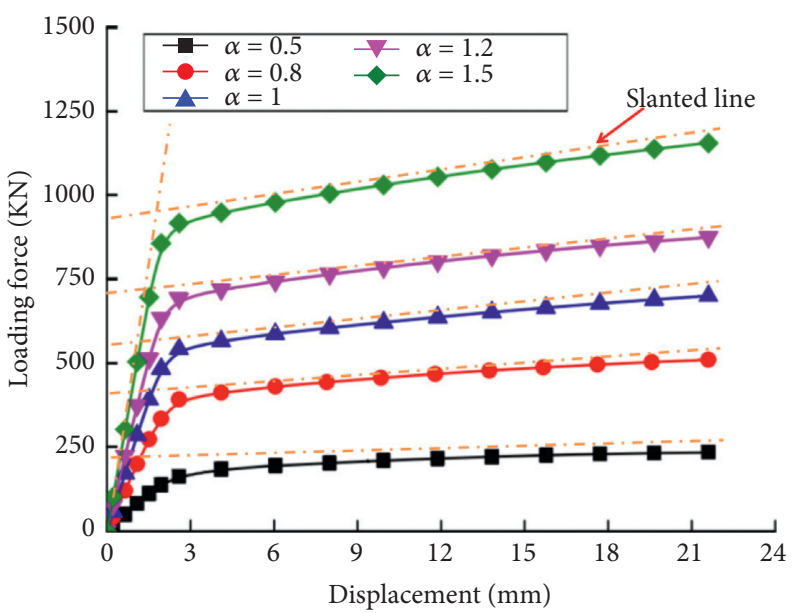

(c)

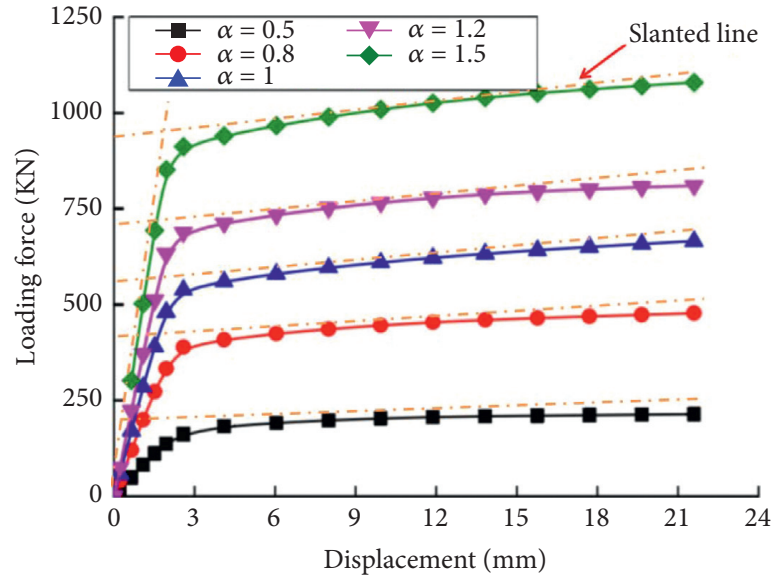

(b)

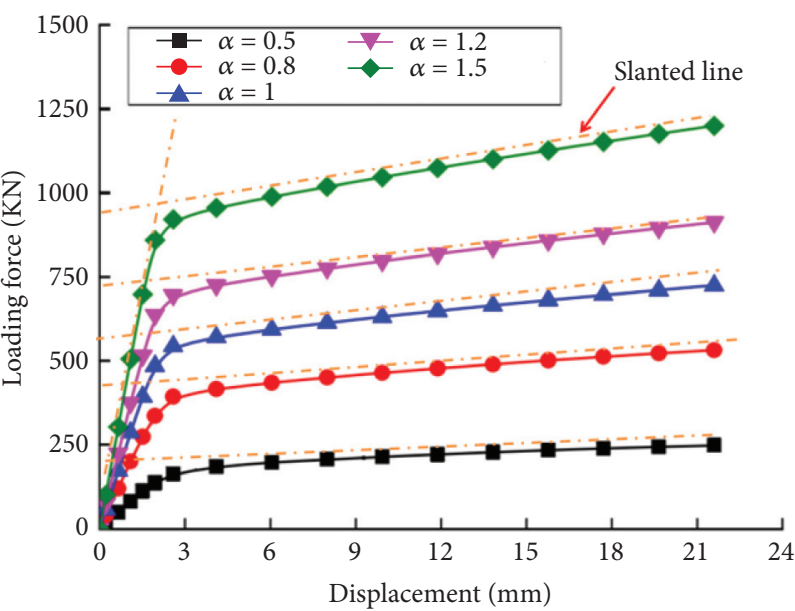

(d)

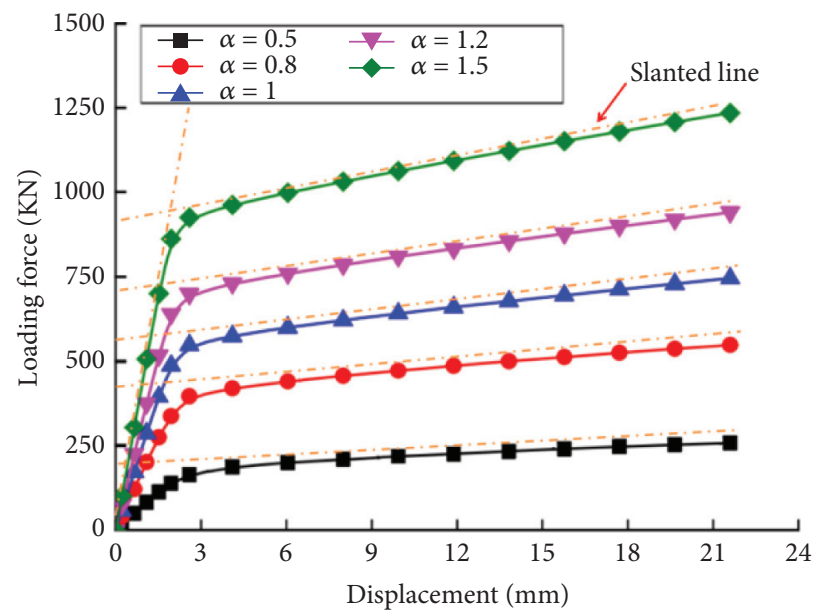

(e)

Figure 5: The relationship of loading force with displacement at different polymer thicknesses. (a) The polymer thickness is $10 \mathrm{~mm}$. (b) The polymer thickness is $15 \mathrm{~mm}$. (c) The polymer thickness is $20 \mathrm{~mm}$. (d) The polymer thickness is $25 \mathrm{~mm}$. (e) The polymer thickness is 30 mm.

be expressed as $C$ in $\mathrm{N} / \mathrm{m}$. It can be obtained by steps according to the calculation formula of displacement in structural mechanics, and the in-plane force of steel panelpolymer composite structure can be regarded as a constant at both ends. Under the action of its longitudinal load $F_{1}$, the total displacement $\Delta y$, buckling deformation $\Delta y_{1}$, and shear deformation $\Delta y_{2}$ can be caused by longitudinal shear and bending deformation. 

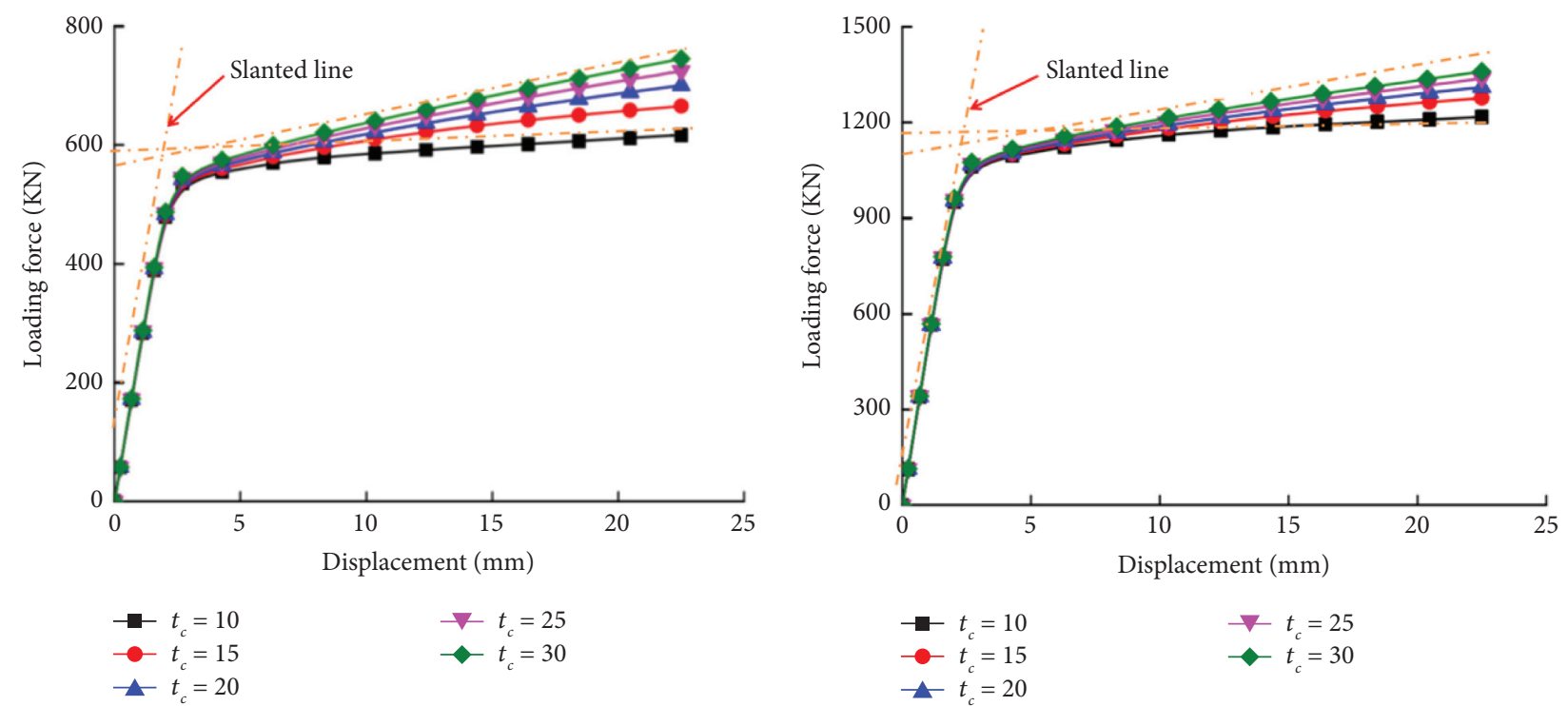

(a)
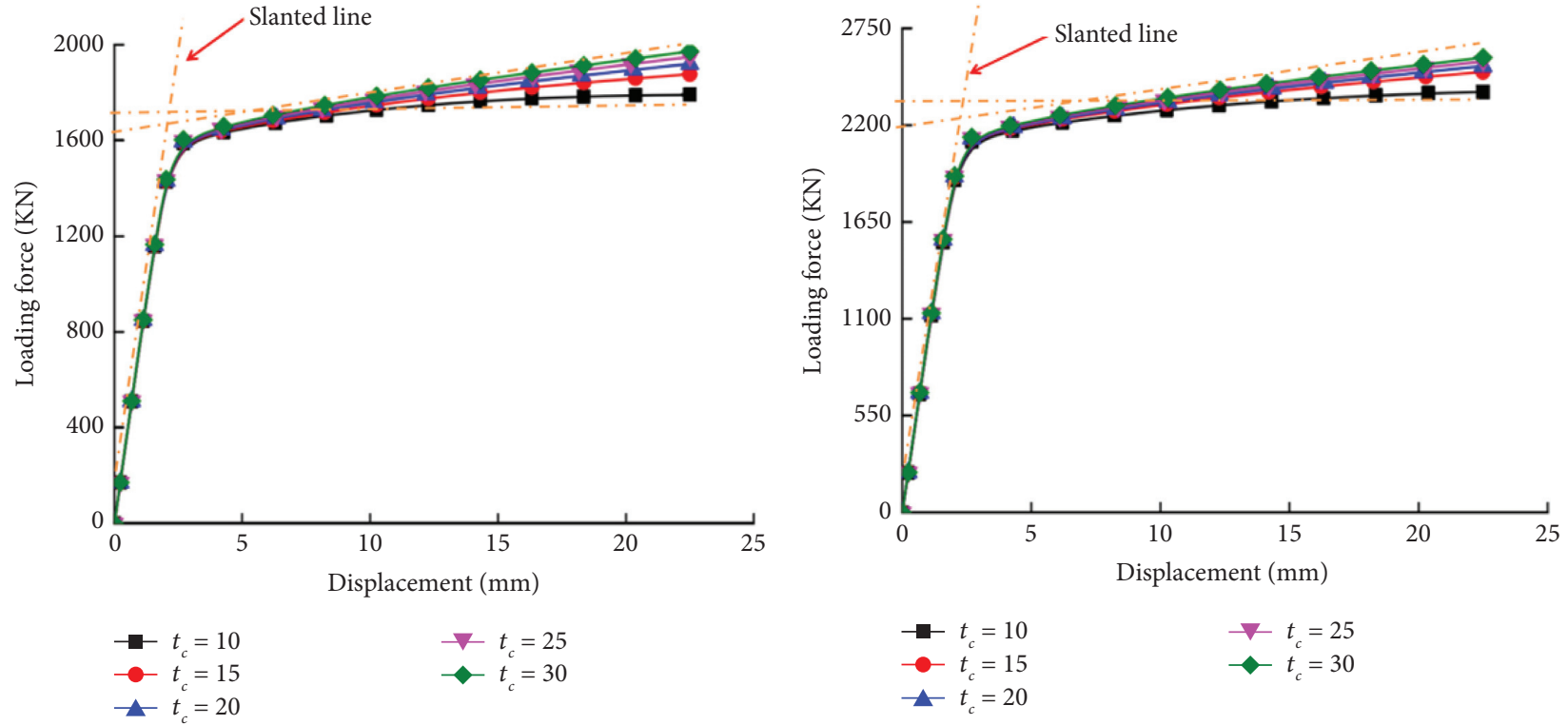

(c)

(d)

FIGURE 6: The relationship of loading force with displacement at different thickness of steel panels (a) The thickness of the steel panel is $3 \mathrm{~mm}$ (b) The thickness of the steel panel is $6 \mathrm{~mm}$ (c) The thickness of the steel panel is $9 \mathrm{~mm}$ (d) The thickness of the steel panel is $12 \mathrm{~mm}$.

The displacement caused by buckling deformation can be expressed as [29].

$$
\Delta y_{1}=\frac{F_{1}}{G_{1} t_{f}(h / l)^{3}},
$$

where $h$ is the longitudinal stiffness of the steel panel, $l$ is the transverse length of the steel panel, $t_{f}$ is the thickness of the steel panel-polymer layer, $G_{1}$ is the elastic modulus of the steel panel, and the displacement caused by shear deformation is

$$
\Delta y_{2}=\frac{2(1+v) F_{1}}{G_{1} t_{f}(h / l)}
$$

where Poisson's ratio $v$ is set as 0.25 .

Then, the following can be obtained from the joint solution of equations $(5) \sim(6)$ :

$$
\Delta y=\frac{F_{1}}{G_{1} t_{f}}\left[\frac{2(1+v)(h / l)^{2}+1}{(h / l)^{3}}\right] .
$$

The vertical shear force $F_{1}$ and vertical displacement $\Delta y$ at the elastic stage exhibit the following relationship: 


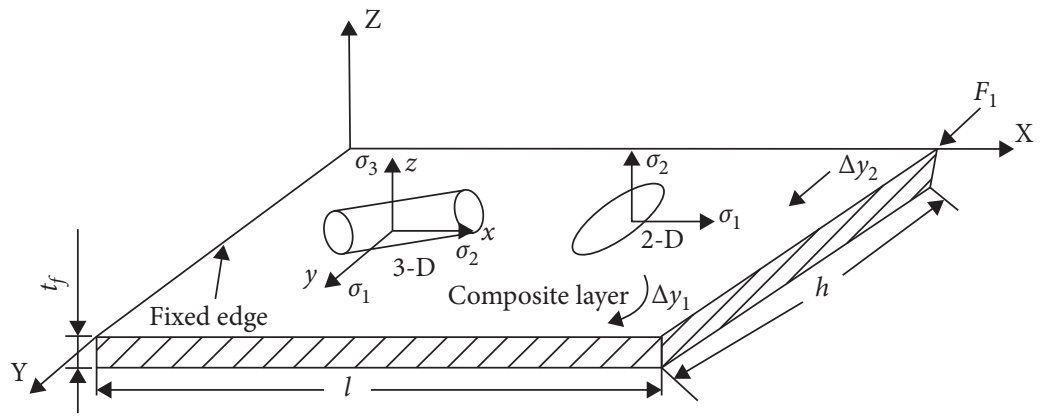

FIGURE 7: Stress analysis [29].

$$
F_{1}=C \cdot \Delta y .
$$

Thus, from equations (5)-(8), the following relationship is derived [29]:

$$
\begin{aligned}
C & =\frac{F_{1}}{\Delta y} \\
& =\frac{F_{1}}{\Delta y_{1}+\Delta y_{2}} \\
& =\frac{G t_{f}}{2(h / l)(1+v)+(h / l)^{3}} .
\end{aligned}
$$

\section{Loading Cycles}

In order to study the hysteresis characteristics of the steel panel-polymer composite structure under cyclic loading, deformation of the composite structure was analyzed to reflect its overall mechanical properties, and the yield stress of the composite structure was achieved. Then, based on load performance parameters, the yield displacement and load of steel panel-polymer composite structure were obtained, as can be seen from Figure 8.

\section{Cyclic Loading and Hysteresis Characteristics}

In order to study the performance and stability of the composite steel panel-polymer layer structure, hysteresis properties of the composite structure were analyzed. Under cyclic loading, the horizontal load at the vertex of the steel panel increased, i.e., hysteresis curve shown in Figure 9. Based on the curve, the performance parameters could be analyzed. According to the analysis, the shrinkage degree of hysteresis curve of steel panel structure was significantly different from that of steel panel-polymer composite structure. Although there existed a slight decrease for the steel panel-polymer composite structure under cyclic loading, the overall load capacity was much higher than that of the steel panel alone. The load bearing capacity of steel panel-polymer composite structure increased by $17.2 \%$ (forward) and $19.3 \%$ (reverse), respectively. According to the initial stiffness, it can be seen from the hysteresis curve that the overall stiffness of steel panel and polymer was smaller than that of single steel panel. Comprehensive analysis shows that the steel panel-polymer composite structure achieved better hysteresis performance and the polymer material improved the bearing capacity of the composite structure, as shown in Figure 9.

According to the shear strength characteristics of steel panel-polymer with different height-to-length shown in Figure 10, when the height-length ratio $a$ was 0.5 , the hysteresis curve of the steel panel-polymer composite structure was plumper. When $a=1$, the hysteresis curve exhibited a certain degree of shrinkage. The stress behaviour of the steel-polymer composite structure showed resilient characteristics. Besides, the design height-to-length ratio from the characteristic increased, and the composite structure presented larger extent, since the half-wave band reduced the bearing capacity of the steel panel-polymer composite structure during the phase formation and phase transformation. Then, the hysteresis curve of the composite structure exhibited pinching shrinkage by the half-wave band. With the shrinkage increasing, the hysteresis curve decreased. Therefore, for a composite structure with a larger height-to-length ratio, the hysteresis curve displayed more shrinkage, whilst with a minimum ratio of 0.5 , the structure exhibited better hysteresis performance, as shown in Figures 10(a) and 10(b).

The overall mechanical properties of steel panel-polymer composite structures can be compared by the area of hysteresis loop. The variation curve of loop area was obtained. Under the first loading, the hysteresis loop area of the steel panel structure and the composite structure reached about zero. It was mainly attributed to that at the elastic stress stage, the steel panel-polymer composite structure showed small deformation and decreasing energy consumption. However, under the subsequent loading, the hysteresis loop area of the steel panel-polymer composite structure gradually increased with the rise of load levelling. The overall performance of the steel panel structure was not consistent with that of the composite structure. The hysteresis loop area of the composite structure was larger than that of single steel panel structure. The hysteresis loop area in the upper loop stage was about $30 \%$ larger than in the initial stage, and therefore, it may prove that the steel panel showed better hysteresis performance after incorporating the polymer layer. It will help to improve the integrity of the flexible structure, which will significantly elevate the overall performance of the steel-polymer layer composite structure, as shown in Figure 11. 


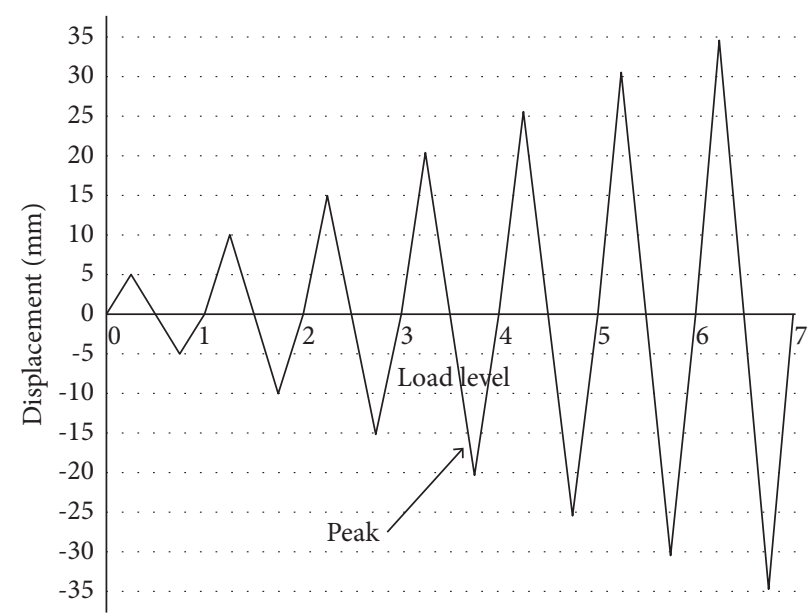

FIgURE 8: Horizontal cyclic reciprocating displacement load [29].

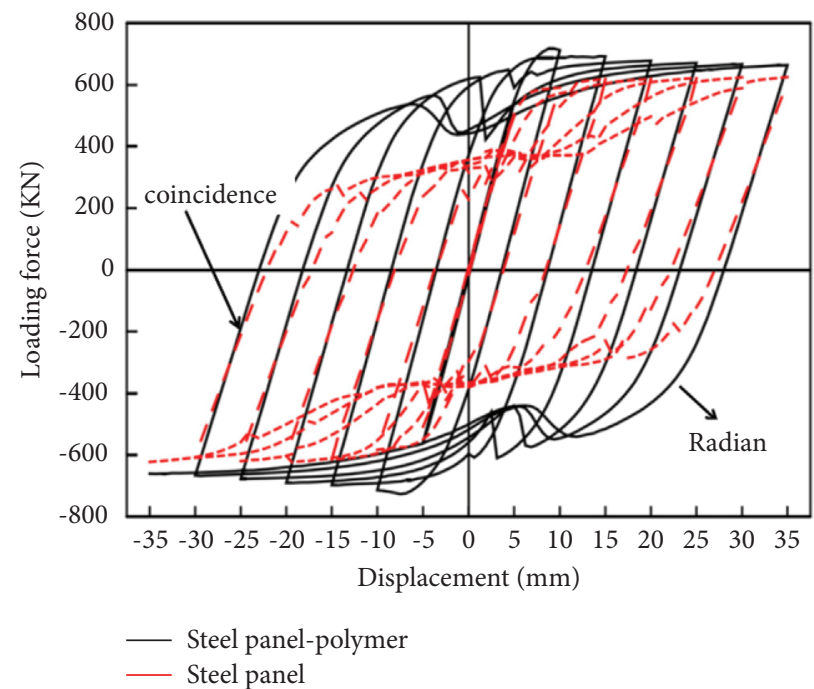

Figure 9: Comparison of carrying capacity between steel panel and steel panel-polymer structure.

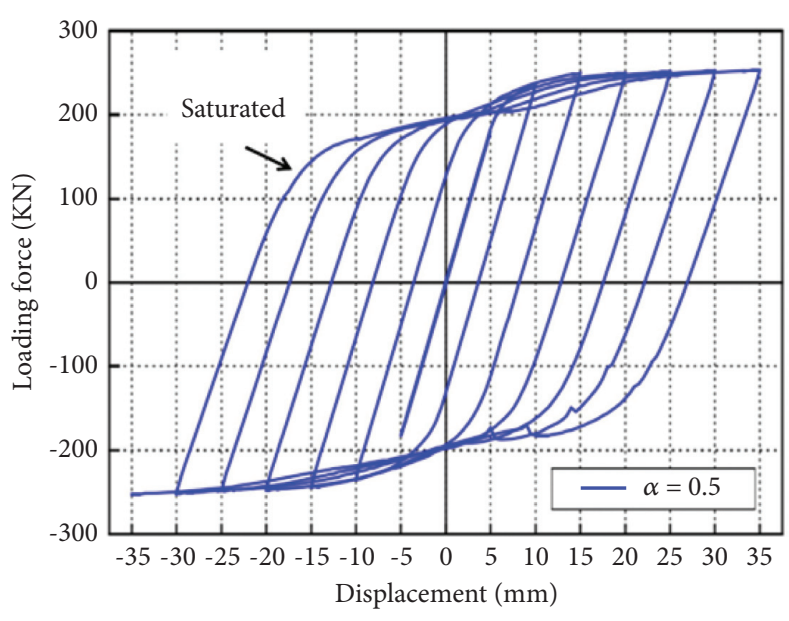

(a)

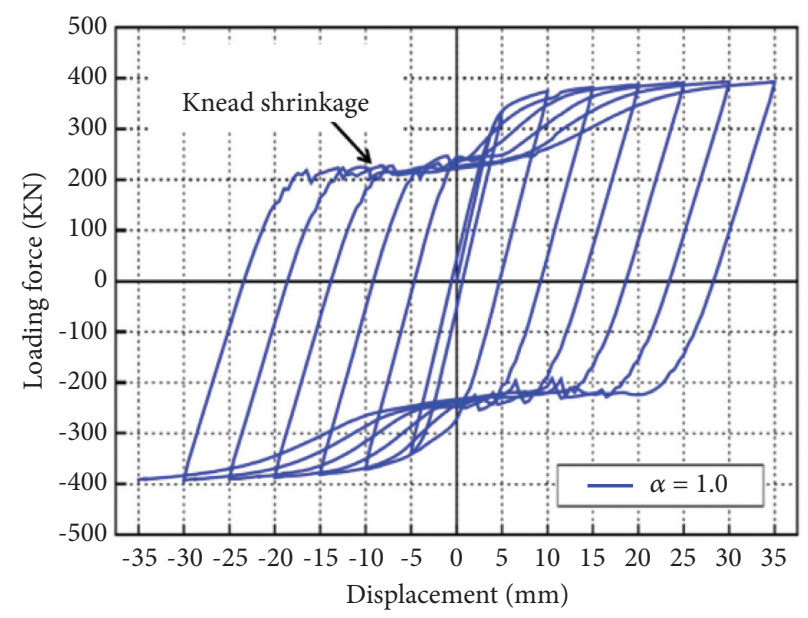

(b)

Figure 10: Influence of height-to-length ratio. (a) The ratio of height to length is 0.5 . (b) The ratio of height to length is 1. 


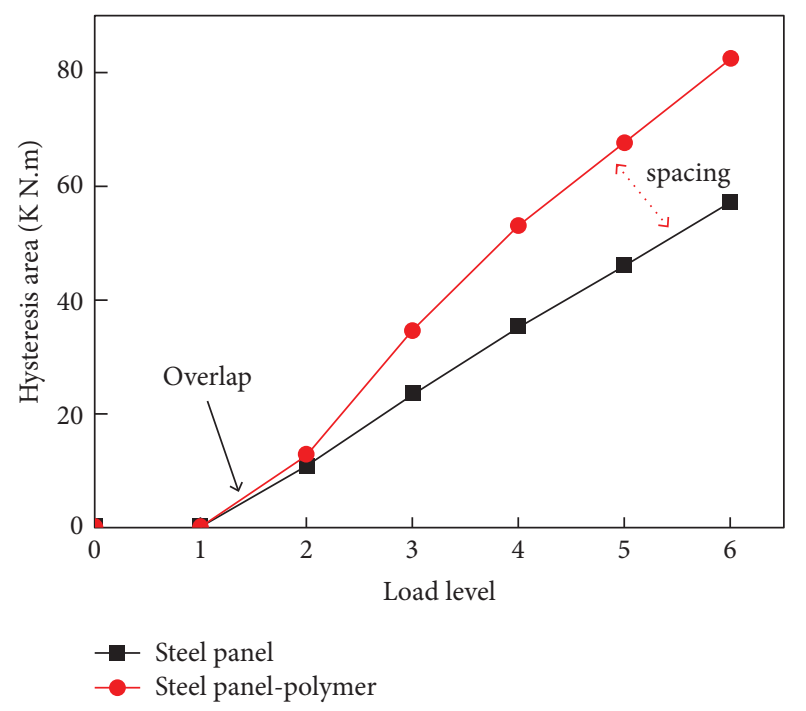

Figure 11: Comparison of hysteresis loop area.

\section{Conclusions}

The new underground foundation pit supporting structure has the advantages of good stability, recyclable usage, quick construction, and low cost. Additionally, it has a wide application prospect. The mechanical properties of steel panelpolymer composite structure were studied. The thicknesses of the polymer layer and the steel panel and the height-tolength ratio of the composite structure were changed to analyze the shear force with the addition of a downward force in the longitudinal direction of the structure. The effects of steel panel thickness and polymer thickness on the stress of the whole structure were obtained. Besides, the overall resilient and hysteresis characteristics of the composite structure were analyzed, which may provide reference for the design of the composite steel panel-polymer composite structure.

(1) The polymer composition was optimized. The polymer grouting material reacted with a certain proportion at $80^{\circ} \mathrm{C}$ for 2 hours in terms of isocyanate and polyether polyols dehydrated at $110^{\circ} \mathrm{C}$, and then $10 \%-30 \%$ diluent, $0.2 \%-1 \%$ surfactant, $0.1 \%-0.5 \%$ catalyst, and 5\%-10\% flame retardant were added. The mixture contained $36 \%$ of phosphorus-containing flame retardants, $15 \%$ of the physical foaming agent, $2 \%$ of the amine catalyst, $1 \%$ of silicon surface active agent, and $1 \%$ of the chemical foaming agent (water). The design was calculated according to the percentage in mass.

(2) The increased thickness of the steel panel and the addition of polymer layer significantly increased the overall mechanical performance of the composite structure, while the thickness of the polymer exhibited slight effects on the overall mechanical properties. According to the requirement on the minimum thickness of polymer, the flexible waterproof layer should be designed as above $10 \mathrm{~mm}$. Considering the overall economy of steel panel and polymer, the thickness of the steel panel should be designed as more than $3 \mathrm{~mm}$.

(3) The force components between the steel panelpolymer composite and the steel pile were generally static, and the structure subsided on both sides of the pile foundation. The static force was transferred to the middle panel by the shear force, and the underground prefabrication shear force increased as the thickness of the steel panel and the height-tolength ratio increased. The increased thickness of the steel panel and the height-to-length ratio caused larger vertical shearing resistance, and then the cross section of the action increased. Thus, the overall static performance was promoted.

(4) In the assembled structure of underground engineering with the steel panel and polymer composite structure, the steel panel and polymer layer exerted their respective superiorities and performed with mutual supplementary. In the process of calculation, the mechanical formula of forces in steel panel and polymer layer was derived, which can be compared with the results of numerical analysis and experimental studies. It may lay the foundation for the overall design of the steel panel-polymer structure in underground engineering.

\section{Data Availability}

The data used to support the findings of this study are available from the corresponding author upon request.

\section{Conflicts of Interest}

The authors declare that they have no conflicts of interest regarding this paper.

\section{Acknowledgments}

This research presented was funded by the Guangzhou Postdoctoral Research Project (62104383).

\section{References}

[1] T. Gong, A. A. Heravi, G. Alsous, I. Curosu, and V. Mechtcherine, "The impact-tensile behavior of cementitious composites reinforced with carbon textile and short polymer fibers," Applied Sciences, vol. 9, no. 19, Article ID 4048, 2019.

[2] Q. H. Cheng, H. P. Lee, and C. Lu, "A numerical analysis approach for evaluating elastic constants of sandwich structures with various cores," Composite Structures, vol. 74, no. 2, pp. 226-236, 2006.

[3] C. Guo, B. Sun, D. Hu, F. Wang, M. Shi, and X. Li, "A field experimental study on the diffusion behavior of expanding polymer grouting material in soil," Soil Mechanics and Foundation Engineering, vol. 56, no. 3, pp. 171-177, 2019.

[4] J. M. Martín-Martínez, T. G. Maciá-Agullo, J. C. FernándezGarcía, A. C. Orgiles-Barceló, and A. Torró-Palau, "Properties of solvent based polyurethane adhesives containing fumed silicas," Macromolecular Symposia, vol. 108, no. 1, pp. 269-278, 1996. 
[5] L. Jiang, Y. C. Lam, K. C. Tam, D. T. Li, and J. Zhang, "The influence of fatty acid coating on the rheological and mechanical properties of thermoplastic polyurethane (TPU)/ nano-sized precipitated calcium carbonate (NPCC) composites," Polymer Bulletin, vol. 57, no. 4, pp. 575-586, 1996.

[6] Á. Sonia and M. M. José, "Effect of the carbon black content on the thermal, rheological and mechanical properties of thermoplastic polyurethanes," Journal of Adhesion Science and Technology, vol. 29, no. 11, pp. 1136-1154, 2015.

[7] I. S. Gunes, G. A. Jimenez, and S. C. Jana, "Carbonaceous fillers for shape memory actuation of polyurethane composites by resistive heating," Carbon, vol. 47, no. 4, pp. 981-997, 2009.

[8] S. A. Abdullah, A. Iqbal, and L. Frormann, "Melt mixing of carbon fibers and carbon nanotubes incorporated polyurethanes," Journal of Applied Polymer Science, vol. 110, no. 1, pp. 196-202, 2008.

[9] B. J.-P. Adohi, A. Mdarhri, C. Prunier, B. Haidar, and C. Brosseau, "A comparison between physical properties of carbon black-polymer and carbon nanotubes-polymer composites," Journal of Applied Physics, vol. 108, no. 7, Article ID 074108, 2010.

[10] M. M. Rahman, E. Y. Kim, K. T. Lim, and W.-K. Lee, "Morphology and properties of waterborne polyurethane/ CNT nanocomposite adhesives with various carboxyl acid salt groups," Journal of Adhesion Science and Technology, vol. 23, no. 6, pp. 839-850, 2009.

[11] M. Fernández, M. Landa, M. A. Muñoz, and A. Santamaria, "Thermal and viscoelastic features of new nanocomposites based on a hot-melt adhesive polyurethane and multi-walled carbon nanotubes," Macromolecular Materials and Engineering, vol. 295, no. 11, pp. 1031-1041, 2010.

[12] G. L. Burkholder, Y. W. Kwon, and R. D. Pollak, "Effect of carbon nanotube reinforcement on fracture strength of composite adhesive joints," Journal of Materials Science, vol. 46, no. 10, pp. 3370-3377, 2011.

[13] F. Li, L. Qi, J. Yang, M. Xu, X. Luo, and D. Ma, "Polyurethane/ conducting carbon black composites: structure, electric conductivity, strain recovery behavior, and their relationships," Journal of Applied Polymer Science, vol. 75, no. 1, pp. 68-77, 2000.

[14] M. Kozlowski, "Electrically conductive structured polymer blends," Polym. Networks Blends, vol. 5, pp. 163-172, 1995.

[15] K. C. Kil, G. Y. Kim, C.-W. Cho et al., "Acid-base interaction between carbon black and polyurethane molecules with different amine values: dispersion stability of carbon black suspension for use in lithium ion battery cathodes," Electrochimica Acta, vol. 111, pp. 946-951, 2013.

[16] E. Andreoli, K.-S. Liao, A. Cricini et al., "Carbon black instead of multiwall carbon nanotubes for achieving comparable high electrical conductivities in polyurethane-based coatings," Thin Solid Films, vol. 550, pp. 558-563, 2014.

[17] Y.-F. Du, P.-W. Shi, Q.-Y. Li, Y.-C. Li, and C.-F. Wu, "Effect of poly(sodium 4-styrenesulfonate) modified carbon black on the dispersion and properties of waterborne polyurethane nanocomposites," Colloids and Surfaces A: Physicochemical and Engineering Aspects, vol. 454, pp. 1-7, 2014.

[18] J. Donate-Robles, C. M. Liauw, J. M. Martín-Martínez, and J. Miguel, "Flow micro-calorimetry and diffuse reflectance Fourier transform infrared spectroscopy studies in filled polyurethane adhesives by using dimethyl adipate as a model compound," International Journal of Adhesion and Adhesives, vol. 48, pp. 43-50, 2014.
[19] X. Lan, W. Huang, and J. Leng, "Shape memory effect in micro-sized shape memory polymer composite chains," Applied Sciences, vol. 9, no. 14, p. 2919, 2019.

[20] D. K. Chattopadhyay and K. V. S. N. Raju, "Structural engineering of polyurethane coatings for high performance applications," Progress in Polymer Science, vol. 32, no. 3, pp. 352-418, 2007.

[21] K. Shimizu, M.-L. Abel, C. Phanopoulos, S. Holvoet, and J. F. Watts, "The characterisation of the interfacial chemistry of adhesion of rigid polyurethane foam to aluminium," Journal of Materials Science, vol. 47, no. 2, pp. 902-918, 2012.

[22] D. V. Palaskar, A. Boyer, E. Cloutet et al., "Original diols from sunflower and ricin oils: synthesis, characterization, and use as polyurethane building blocks," Journal of Polymer Science Part A: Polymer Chemistry, vol. 50, no. 9, pp. 1766-1782, 2012.

[23] H. Beneš, J. Rösner, and P. Holler, "Glycolysis of flexible polyurethane foam in recycling of car seats," Polymers for Advanced Technologies, vol. 18, no. 2, pp. 149-156, 2007.

[24] Q. Zhu, Y. Ding, D. Tu, H. Zhang, and Y. Peng, "Experimental study of defect localization in a cross-ply fiber reinforced composite with diffuse ultrasonic waves," Applied Sciences, vol. 9, no. 11, p. 2334, 2019.

[25] B. Pukánszky Jr, K. Bagdi, and Z. Tóvlgyi, "Nanophase separation in segmented polyurethane elastomers: effect of specific interactions on structure and properties," European Polymer Journal, vol. 44, no. 8, pp. 2431-2438, 2008.

[26] D. P. Hu, C. C. Guo, and X. X. Chu, "Application, synthesis, isocyanate and polyol in underground seepage control engineering," Journal of the Indian Chemical Society, vol. 97, pp. 1548-1556, 2020.

[27] C. Guo, D. Hu, and F. Wang, "Diffusion behavior of polymer grouting materials in sand and gravel," Soil Mechanics and Foundation Engineering, vol. 57, no. 6, pp. 440-444, 2021.

[28] F. Wang, Y. Fan, C. Guo, L. Qin, and D. Hu, "Finite element simulation of rock mechanical properties in rock surrounding a deep tunnel with water leakage," Soil Mechanics and Foundation Engineering, vol. 57, no. 2, pp. 127-132, 2020.

[29] D. Dengping Hu, C. Guo, and X. Chu, "Hysteretic characteristic curve monitoring and finite element analysis in nondestructive testing of fabricated foundation pit," Russian Journal of Nondestructive Testing, vol. 56, no. 9, pp. 752-764, 2020.

[30] D. Dengping Hu, C. Guo, and X. Chu, "Nondestructive sensor detection and economic applicability analysis of underground foundation pit," Russian Journal of Nondestructive Testing, vol. 56, no. 8, pp. 681-688, 2020.

[31] D. Hu, C. Guo, and X. Chu, "Case study of flexible prefabricated impermeable underground support structure[J]," Iranian Journal of Science and Technology, Transactions of Civil Engineering, vol. 45, no. 4, pp. 2489-2501, 2021.

[32] A. I. Derivatives and I. Lignosulfonates, "Influence of processing conditions on the thermal stability and mechanical properties of PP/Silica-Lignin composites," International Journal of Polymer Science, vol. 1, pp. 1-9, 2016.

[33] D. Zhou and W. J. Stronge, "Mechanical properties of fibrous core sandwich panels," International Journal of Mechanical Sciences, vol. 47, no. 4-5, pp. 775-798, 2005.

[34] D. Hu, C. Guo, and X. Chu, "Engineering case study of twocomponent polymer grouting anchorage behind the steel panel," Basic and Clinical Pharmacology and Toxicology, vol. 126, pp. 258-259, 2020.

[35] H.-S. Jung, B.-I. Bae, H.-K. Choi, J.-H. Chung, C.-S. Choi, and Y.-C. Choi, "Experimental and numerical study on the compression behavior of square concrete-filled steel tube stub 
columns with steel fiber-reinforced high-strength concrete," International Journal of Polymer Science, vol. 2018, Article ID 2385725, 13 pages, 2018.

[36] D. Hu and C. Guo, "Comparison of properties and engineering application of isocyanate/polyol waterproof materials," New Building Materials, vol. 46, no. 9, pp. 160-164, 2019, In Chinese.

[37] D. Hu and G. Chengchao, "Composition and property analysis of polyurethane composites for construction engineering," Engineering Plastics Application, vol. 47, no. 8, pp. 109-113, 2019, In Chinese.

[38] M. He and W. Hu, "A study on composite honeycomb sandwich panel structure," Materials \& Design, vol. 29, no. 3, pp. 709-713, 2008.

[39] E. M. Reis and S. H. Rizkalla, "Material characteristics of 3-D FRP sandwich panels," Construction and Building Materials, vol. 22, no. 6, pp. 1009-1018, 2008.

[40] X. Liu, T. Wang, L. C. Chow, M. Yang, and J. W. Mitchell, "Effects of inorganic fillers on the thermal and mechanical properties of poly(lactic acid)," International Journal of Polymer Science, vol. 2014, Article ID 827028, 8 pages, 2014.

[41] R. C. Petersen, "Bisphenyl-polymer/carbon-fiber-reinforced composite compared to titanium alloy bone implant," International Journal of Polymer Science, vol. 3476, pp. 23412348, 2011.

[42] X. Gao, H. Wei, W. Ya, and Y. Zhong, "Experiment and modeling for compressive strength of polyurethane grout materials," Acta Materiae Compositae Sinica, vol. 34, no. 2, pp. 438-445, 2017.

[43] X. Gao, Y. Wei, F. Wang, and Y. Zhong, "Fatigue resistant and microstructure evolution of polyurethane grout materials under uniaxial compression," Acta Materiae Compositae Sinica, vol. 34, no. 3, pp. 550-556, 2017.

[44] Y. Pan, H. Fang, B. Li, and F. Wang, "Stability analysis and full-scale test of a new recyclable supporting structure for underground ecological granaries," Engineering Structures, vol. 192, pp. 205-219, 2019.

[45] H. Yao, Q. Dai, Z. You, J. Zhang, S. Lv, and X. Xiao, "Evaluation of contact angle between asphalt binders and aggregates using Molecular Dynamics (MD) method," Construction and Building Materials, vol. 212, pp. 727-736, 2019.

[46] H. Yao, Q. Dai, Z. You, A. Bick, and M. Wang, "Modulus simulation of asphalt binder models using Molecular Dynamics (MD) method," Construction and Building Materials, vol. 162, pp. 430-441, 2018.

[47] H. Yao, Q. Dai, Z. You, A. Bick, M. Wang, and S. Guo, "Property analysis of exfoliated graphite nanoplatelets modified asphalt model using molecular dynamics (MD) method," Applied Sciences, vol. 7, no. 1, p. 43, 2017.

[48] Z. Deng, H. Huang, B. Ye, P. Xiang, and C. Li, "Mechanical performance of RAC under true-triaxial compression after high temperatures," Journal of Materials in Civil Engineering, vol. 32, no. 8, Article ID 04020194, 2020.

[49] A. Zhd, A. Hqh, C. By, W. Huaping, and P. Xiang, "Investigation on recycled aggregate concretes exposed to high temperature by biaxial compressive tests," Construction and Building Materials, vol. 244, no. 4, 2020.

[50] A. Shaat and A. Fam, "Fiber-element model for slender HSS columns retrofitted with bonded high-modulus composites," Journal of Structural Engineering, vol. 133, no. 1, pp. 85-95, 2007.

[51] J. Aguilera and A. Fam, "Retrofitting tubular steel T-joints subjected to axial compression in chord and brace members using bonded FRP plates or through-wall steel bolts-ScienceDirect," Engineering Structures, vol. 48, pp. 602-610, 2013.

[52] J. Aguilera and A. Fam, "Bonded FRP plates for strengthening rectangular hollow steel section $\mathrm{T}$-joints against web buckling induced by transverse compression," Journal of Composites for Construction, vol. 17, no. 4, pp. 421-432, 2013.

[53] J. Lei, Y. Liu, and F. Amir, "Stress concentration factors in joints of square hollow section (SHS) brace and concrete-filled SHS chord under axial tension in brace," Thin-Walled Structures, vol. 132, pp. 79-92, 2018. 